\title{
Assigning value to preparation for prostate cancer decision making: a willingness to pay analysis
}

Leslie S. Wilson ${ }^{1}$, Traci M. Blonquist ${ }^{2}$, Fangxin Hong ${ }^{2}$, Barbara Halpenny ${ }^{2}$, Seth Wolpin ${ }^{3}$, Peter Chang ${ }^{4}$, Christopher P. Filson ${ }^{5}$, Viraj A. Master ${ }^{5}$, Martin G. Sanda ${ }^{5}$, Gary W. Chien ${ }^{6}$, Randy A. Jones ${ }^{7}$, Tracey L. Krupski ${ }^{7}$ and Donna L. Berry ${ }^{2^{*}}$ (D)

\section{Abstract}

Background: The Personal Patient Profile-Prostate (P3P) is a web-based decision support system for men newly diagnosed with localized prostate cancer that has demonstrated efficacy in reducing decisional conflict. Our objective was to estimate willingness-to-pay (WTP) for men's decisional preparation activities.

Methods: In a multicenter, randomized trial of P3P, usual care group participants received typical preparation for decision making plus referral to publicly-available, educational websites. Intervention group participants received the same, plus online P3P educational media specific to the user's personal preferences and values, and a communication coaching component tailored to racelethnicity, age and language. WTP data were collected one week after physician consultation. An iterative bidding direct contingent valuation survey format was used, randomly assigning participants to high or low starting values (SV). Tobit models were used to explore associations between SV-adjusted WTP and age, education, marital and work-status, insurance, decision-control preference and decision-making stage.

Results: Of 392 participants enrolled, 141 P3P and 107 usual care (UC) provided a WTP value. Men were willing to pay a median \$25 (IQR \$10-100) for P3P in addition to usual care preparation materials. In the final multivariable tobit regression model, SV, marital status, stage of decision making and income were significantly associated with WTP for P3P. Decision control preference was considered marginally significant $(p=0.11)$. Men were WTP a median $\$ 30$ (IQR \$10-\$200) for usual care material alone. In the final multivariable model, SV, education, and stage of decision making were significantly associated with WTP in usual care.

Conclusion: WTP was similar for UC and for the addition of P3P to UC decision preparation. The WTP values were associated with demographic and preference variables. Findings can help focus decision support on future patients who would benefit most: those without strong support systems, at earlier stages of decision making, and open to a shared-decision style.

Trial registration: NCT NCT01844999. Registered May 3, 2013.

Keywords: Prostate cancer, Decision aid, Willingness to pay, Shared decision making

\footnotetext{
* Correspondence: donna_berry@dfci.harvard.edu

2Dana-Farber Cancer Institute, 450 Brookline Avenue, Boston, MA 02215, USA

Full list of author information is available at the end of the article
}

(c) The Author(s). 2019 Open Access This article is distributed under the terms of the Creative Commons Attribution 4.0 International License (http://creativecommons.org/licenses/by/4.0/), which permits unrestricted use, distribution, and reproduction in any medium, provided you give appropriate credit to the original author(s) and the source, provide a link to the Creative Commons license, and indicate if changes were made. The Creative Commons Public Domain Dedication waiver (http://creativecommons.org/publicdomain/zero/1.0/) applies to the data made available in this article, unless otherwise stated. 


\section{Background}

The use of decision aids to promote shared decision making is especially important in prostate cancer treatment decisions, a condition in which personal values and preference regarding risks of treatment side effects influence the patient's choice [1-3]. The Personal Patient Profile-Prostate (P3P) is a web-based decision support system that has been shown to decrease decisional conflict in men newly diagnosed with localized prostate cancer $[4,5]$. Despite evidence of the value of decisions aids, uptake in the United States remains low and economic value may be an important factor. U.S. health care systems, third-party payers and often, providers, want evidence of economic value and patient acceptance before adopting. There is a lack of information about the direct economic value of decision aids precluding providers' and payers' consideration of investments in decision aids [6]. There are few economic evaluations of decision aids because the downstream cost savings are often unavailable for measurement. Further, for value-sensitive decisions there are often no right or wrong choices based purely on clinical evidence. However, after engaging with a decision aid, each user can ascertain the value of the aid. Willingness-to-pay (WTP) then becomes an ideal framework for direct economic valuation of decision aids from the user's viewpoint [7-11] Other non-economic measures, such as decision regret and decisional conflict also can act as measures of an optimal decision choice; [12] these outcomes were part of efficacy testing in our previous clinical trials $[4,5]$.

There are three contemporary approaches to the measurement of WTP, all of which have been used to find the maximum price a person is willing to pay for a given quantity of a good: 1) contingent valuation, a stated preference approach in which the consumer is directly asked their WTP for a total good; 2) experimental auction, a revealed preference approach where persons are provided actual money and asked to behave in a market of goods, or observed directly in transactions; and 3) conjoint analysis, a stated preference approach where WTP is derived from ranking, rating or selection of goods alternatives by attributes [13]. The choice of method is primarily driven by cost, ease of use, whether or not the good is currently available in the market, the desire for pricing or utility, and whether the estimated WTP is likely to mimic actual market place behavior [14].

The purpose of this study was to estimate clinical trial participants' WTP for the P3P during the time of decision making for localized prostate cancer care. We also present data on the WTP reported for the control group who received a variety of other 'usual care' preparations.

\section{Methods}

\section{Sample and settings}

A multi-center randomized trial was conducted with a primary outcome of decisional conflict. Detailed methods and outcomes were described in a previous publication [5]. Patients were eligible with: 1) a biopsy-proven diagnosis of prostate cancer, cT1 or cT2 of any risk level; 2) an upcoming consult at an enrolling study site; and 3) self-reported ability to read and understand English or Spanish. Participant accrual was from two urology clinics of Kaiser Permanente Southern California, urology and radiation oncology clinics at Beth Israel Deaconess Medical Center in Boston, the University of Massachusetts Memorial Hospital in Worcester, Lyndon B Johnson Hospital urology department in Houston, a community clinic in western New York, four urology clinics in Atlanta's Emory University network and urology services of University of Virginia Health System. The populations of men with prostate cancer at the sites were diverse regarding race, ethnicity and income [5]. The sites included both membershipbased health care institutions, with presumably fewer out of pocket costs, and traditional third-party payer institutions, but out of pocket costs were not measured in this study.

\section{Design and intervention}

While conducting a randomized trial of the P3P Webbased decision aid among men newly diagnosed with localized prostate cancer, we collected WTP data one week after a consult with a prostate cancer physician [15]. The P3P website was accessible on any Web-enabled device for use after the prostate cancer diagnosis and prior to physician consultation. After users answered questions about preferences and decision factors, each was randomized to P3P intervention or usual care (UC). The P3P education and coaching intervention content was targeted to address individuals' responses, with video clips tailored to race, age and language (English or Spanish). Non-tailored teaching sheets were provided on-screen and in printable format covering eight standard topics in prostate cancer education. Finally, a list of other reputable prostate cancer educational websites was presented to users in both groups. Routinely distributed materials or recommendations in each clinic were provided P3P group participants were asked their WTP for only the P3P intervention, while the UC group was asked their WTP for the list of websites and any other education they reported receiving or finding We considered WTP for P3P to be additional to this education at each site as all participants had access to these resources.

WTP approach: Stated preference vs revealed preference The direct contingent evaluation WTP approach was selected for this study, first, for its ease of use when 
eliciting information from patients at a stressful time after a cancer diagnosis. Secondly, P3P was not on the market for evaluation by actual use and was not directly paid for by the patient, precluding measuring market behavior. Finally, because the decision aid offered education in a context where there is no right or wrong choice, the use of the other methods to assess optimal choice or medical savings was not possible. In addition, we were interested in a direct price value, rather than price as one factor of a mixed utility evaluation (e.g., conjoint analyses). Despite some methodological limitations of WTP approach to measure more theoretical environmental value questions, it remains a favored approach for determining health care value $[16,17]$.

\section{Telephone survey}

An iterative bidding direct contingent valuation survey format, delivered by telephone one week after consultation with a physician, was used to elicit the WTP. Participants were randomly assigned, stratified by institutional site, to either a high (\$200) or low (\$10) starting value (SV) to enable control for starting point bias. The starting points were based on a previous WTP study of a decision aid used in breast cancer patients [18]. Based on the first WTP value, participants were asked if they were willing to pay alternately higher and lower values until the maximum WTP was reached, at which point the final maximum WTP was confirmed. While bidding game formats may result in higher valuations than open ended payment formats, all suffer from anchoring effects. Bidding formats exclusively obtain the maximum WTP, whereas payment ranges eliminate knowing if a person's choice is a maximum or minimum payment preference [19].

The survey was delivered by telephone to both the P3P intervention and usual care (UC) groups. A research coordinator read scripted instructions and asked respondents to consider the materials they were being asked to value. The P3P group participants were reminded of using the intervention and then were asked "Would you be willing to pay $\$[200 / 10]$ to use P3P?" In the UC group, the script included instructions to describe any materials provided by their hospital, clinic or providers, then reminded them of the standard educational websites they have been given in the P3P program; respondents were then asked "Would you be willing to pay [\$200/\$10] for the materials from your hospital/clinic and the websites from P3P?"

\section{Analysis}

Fisher's exact test was used to evaluate differences in patient characteristics between participants who did and did not provide a WTP value. Reasons for not providing a WTP value were investigated and described qualitatively.
The team decided a priori to analyze WTP separately for the P3P and UC groups to determine the value which participants were willing to pay under the different circumstances of educational support. Associations between SV and the continuous WTP value were evaluated with the Wilcoxon rank sum test. Based on recommendations to match the measure with the purpose of its use, [20] median WTP values were summarized. A WTP demand curve was created by plotting the number of participants willing to pay above a given dollar amount.

Due to the right-skew in WTP values, a $\log ($ WTP +1$)$ transformation was performed and outliers were removed. Tobit regression models, left censored at a value of $\$ 0$, were used to explore the association between SV-adjusted WTP and: age ( $<60$ years, $60-69$ years, $\geq 70$ years), education ( $\leq$ high school, $>$ high school), marital status (not married/partnered, married/partnered), work status (working, not working), income $(<\$ 40,000$, $\$ 40,000-\$ 99,999, \geq \$ 100,000$ ), insurance (Medicare, private, other), decision control preference (active/shared, or passive decision making), and decision making stage (not started, started, close to deciding/decided). Multivariable model-building followed a forward stepwise selection method in which SV was retained. The selection criteria utilized $p$-values with significance levels of 0.2 to be entered and 0.1 to be retained in the model. Tobit regression models were fit using the VGAM [21] package in $\mathrm{R}$ version 3.4 .3 [22]. All other analyses were performed in SAS software version 9.4 of the SAS System for Windows, PC, ( ) 2013, SAS Institute Inc [23].

\section{Results}

Of 577 men contacted, 415 (72\%) enrolled and 392 eligible participants were randomized in the clinical trial from September 2013 through April 2016. [5] We attempted to reach all participants by phone 1-week after the physician consult for the WTP survey. Sixty-six participants (17\%) were not reached; $18(5 \%)$ refused to complete the survey; and $60(15 \%)$ agreed to the survey but were unable or unwilling to provide a WTP value (Table 1). The total number of participants providing a WTP value was 248 (63\%). Overall, not providing a WTP value was associated with being randomized to UC $(p=0.001)$ and, regardless of study group, having high school or lower education $(p=0.047)$.

\section{WTP for P3P intervention}

In the intervention group $(n=198)$, we successfully contacted and obtained a WTP value on the 1-week WTP survey for 141 (71\%) participants. Among the 57 not providing a value, 32 (56\%) were not reached, $6(10 \%)$ refused the questionnaire, and 19 (33\%) agreed to answer the questionnaire but did not provide a final WTP value. Of these 19 men, 12 reported not spending any 
Table 1 Participant characteristics

\begin{tabular}{|c|c|c|c|c|c|c|c|c|c|}
\hline & \multirow{3}{*}{$\begin{array}{l}\text { Overall } \\
\mathrm{N}\end{array}$} & \multicolumn{4}{|c|}{ Provide WTP Amount ${ }^{b}$} & \multicolumn{4}{|c|}{ Study Group ${ }^{c}$} \\
\hline & & \multicolumn{2}{|l|}{$\overline{N o}$} & \multicolumn{2}{|l|}{ Yes } & \multicolumn{2}{|c|}{ P3P } & \multicolumn{2}{|l|}{$U C$} \\
\hline & & $N$ & $\%$ & $\mathrm{~N}$ & $\%$ & $\mathrm{~N}$ & $\%$ & $\mathrm{~N}$ & $\%$ \\
\hline $\mathrm{N}$ & 392 & 144 & 37 & 248 & 63 & 141 & & 107 & \\
\hline \multicolumn{10}{|l|}{ Study Group } \\
\hline Control & 194 & 87 & 45 & 107 & 55 & & & & \\
\hline Intervention & 198 & 57 & 29 & 141 & 71 & & & & \\
\hline \multicolumn{10}{|l|}{ Age } \\
\hline$<59$ years & 125 & 42 & 34 & 83 & 66 & 48 & 34 & 35 & 33 \\
\hline 60-69 years & 196 & 77 & 39 & 119 & 61 & 65 & 46 & 54 & 50 \\
\hline$\geq 70$ years & 71 & 25 & 35 & 46 & 65 & 28 & 20 & 18 & 17 \\
\hline \multicolumn{10}{|l|}{ Education $(n=387)$} \\
\hline$\leq$ High school & 77 & 36 & 47 & 41 & 53 & 20 & 14 & 21 & 20 \\
\hline > High school & 310 & 105 & 34 & 205 & 66 & 120 & 85 & 85 & 79 \\
\hline \multicolumn{10}{|l|}{ Marital Status $(n=389)$} \\
\hline Not married/Partnered & 109 & 43 & 39 & 66 & 61 & 40 & 28 & 26 & 24 \\
\hline Married/Partnered & 280 & 99 & 35 & 181 & 65 & 101 & 72 & 80 & 75 \\
\hline \multicolumn{10}{|l|}{ Work Status $(n=387)$} \\
\hline Not working & 162 & 58 & 36 & 104 & 64 & 51 & 36 & 53 & 50 \\
\hline Working & 225 & 83 & 37 & 142 & 63 & 88 & 62 & 54 & 50 \\
\hline \multicolumn{10}{|l|}{ Income $(n=355)$} \\
\hline$<\$ 40,000$ & 97 & 37 & 38 & 60 & 62 & 35 & 25 & 25 & 23 \\
\hline$\$ 40,000-\$ 99,999$ & 120 & 46 & 38 & 74 & 62 & 39 & 28 & 35 & 33 \\
\hline$\geq \$ 100,000$ & 138 & 42 & 30 & 96 & 70 & 57 & 40 & 39 & 36 \\
\hline \multicolumn{10}{|l|}{ Insurance $(n=387)$} \\
\hline Medicare & 116 & 37 & 32 & 79 & 68 & 43 & 30 & 36 & 34 \\
\hline Private & 194 & 68 & 35 & 126 & 65 & 76 & 54 & 50 & 47 \\
\hline Other ${ }^{a}$ & 77 & 36 & 47 & 41 & 53 & 22 & 16 & 19 & 18 \\
\hline \multicolumn{10}{|l|}{ Preference $(n=381)$} \\
\hline Active & 126 & 39 & 31 & 87 & 69 & 50 & 35 & 37 & 35 \\
\hline Passive/Shared & 255 & 97 & 38 & 158 & 62 & 89 & 63 & 69 & 64 \\
\hline \multicolumn{10}{|l|}{ Stage of Decision $(n=387)$} \\
\hline Not started & 87 & 31 & 36 & 56 & 64 & 36 & 26 & 20 & 19 \\
\hline Started & 187 & 66 & 35 & 121 & 65 & 64 & 45 & 57 & 53 \\
\hline Close/decided & 113 & 45 & 40 & 68 & 60 & 39 & 28 & 29 & 27 \\
\hline
\end{tabular}

WTP = willingness to pay

aOther includes: none, public/private, military, Medicaid

${ }^{\mathrm{b}}$ Row percentages ${ }^{\mathrm{c} C o l u m n}$ percentages

time using P3P, two who spent less than an hour using P3P, one who reported using P3P for 1 to $2 \mathrm{~h}$ but could not determine a value, and one who reported more than $4 \mathrm{~h}$ use and that the information in P3P was "worth a lot," but he could not assign a monetary value. Three men did not report time spent using P3P or the reason(s) for not assigning a value. Participant characteristics for those providing a WTP value in the P3P intervention group are presented in Table 1. No significant differences were detected between those who did or did not provide a WTP value (data not shown). Amount of time spent using P3P was known for 133 participants; the majority (59\%) spent less than $1 \mathrm{~h}$ using P3P, while 44 (33\%) spent 1 to $2 \mathrm{~h}$.

Of the 141 participants who gave a WTP value, 24 (17\%) reported \$0. Participants who chose to comment on the $\$ 0$ value indicated unwillingness to pay for information available on the Internet $(n=5)$ or that sufficient 
information was gathered prior to using P3P $(n=5)$. The remainder reported a WTP from $\$ 1.29$ to $\$ 100,000$. The participant reporting a $\$ 100,000$ value stated P3P was "beyond helpful;" this value was 100 times larger than the next highest value reported. Additionally, the value was more than two standard deviations from the transformed mean and was therefore treated as an outlier in all tobit models. For all reporting, the median WTP for P3P was \$25 (IQR \$10-100) (Additional file 1: Table S1). Overall, WTP value was associated with SV $(p=0.018)$; the median WTP value in those with a low and high SV was \$25 (IQR \$10-\$75) and \$50 (IQR \$22.5-\$200), respectively. The WTP demand curve (Fig. 1) has a steep slope at the highest WTP values and then a flatter curve across other WTP values.

In SV-adjusted univariate tobit regression models, marital status, decision control preference, stage of decision, and income were significantly associated with the predicted WTP value (Additional file 2: Table S2). In the final multivariable model, starting value, marital status, stage of decision making, and income retained significance with $p$-values $<0.10$, and decision preference was considered marginally significant $(p=0.11)$. The resulting model indicated the predicted WTP values for participants randomized to a high SV (compared to a low $\mathrm{SV}$ ) and not married/partnered (compared to married/ partnered) were 2.15 (90\% CI 1.22-3.78) and 2.77 (90\% CI 1.26-6.05) times higher, respectively. The predicted WTP value for participants who had not yet started, or had just started the decision-making process, was 2.81 (90\% CI 1.34-5.89) and 2.34 (90\% CI 2.34-4.53) times higher, respectively, than participants who either decided or were close to a decision at study entry. The predicted WTP value for participants with an income \$40,000-\$99,999 was 2.39 (90\% CI 1.23-4.66) times higher than those with an income $\geq \$ 100,000$; no other significant differences with income were detected (Table S2). The predicted WTP value for participants with a shared/ passive decision-making preference was marginally higher, 1.75 (90\% CI 0.98-3.11) times compared to those with an active decision-making preference.

\section{WTP for usual care}

In UC ( $n=194)$, we reached $107(55 \%)$ men who also reported a WTP value for decision preparation materials. Of the 87 who did not provide a value, 34 (39\%) were not reached, $12(14 \%)$ refused to answer the questionnaire, and 41 (47\%) agreed to answer the questionnaire but did not provide a final WTP value. Among the last group, the most common reason for not providing a WTP value was that no materials were reviewed. Of the 107 participants who provided a value, 99 indicated the type of education support they received, of which the most commonly used were websites $(n=81)$ and brochures/pamphlets $(n=50)$. The majority $(67 \%)$ spent less than $2 \mathrm{~h}$ using these materials. No significant differences were detected between those who provided and did not provide a final WTP value. The median WTP for UC was \$30 (IQR \$10-\$200) with a range of $\$ 0$ to $\$ 5000$ (Table 1). WTP was associated with SV $(p=0.031)$, with a median WTP of $\$ 25$ (IQR $\$ 0-\$ 75)$ and \$50 (IQR \$22-\$200) in low and high SV respectively.

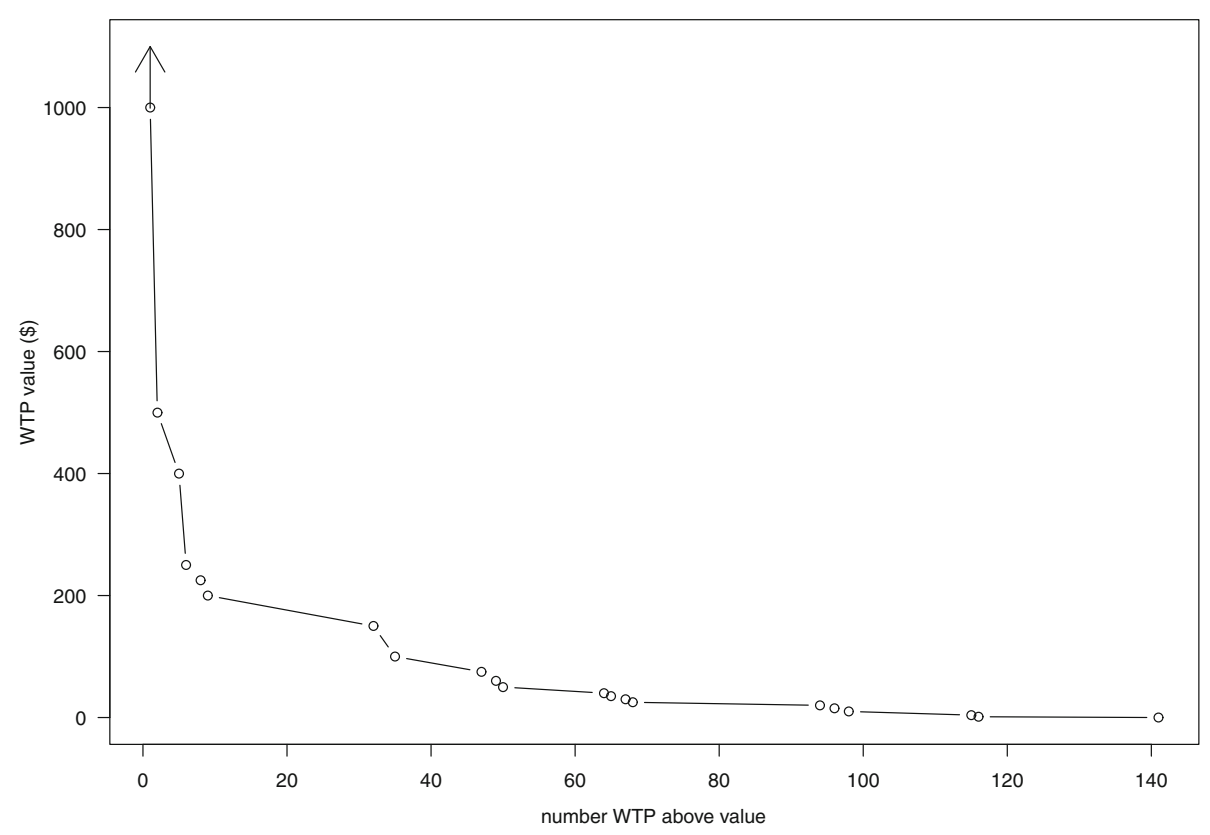

Fig. 1 WTP demand curve for the P3P intervention 
In the SV-adjusted, univariate tobit regression models, education and stage of decision making were significantly associated with the WTP (Additional file 3: Table S3). The final multivariable tobit model included starting value, education, and stage of decision making. The predicted WTP values for those randomized to a high starting value (compared to a low SV) and with a $<$ high school education (compared to > high school education) were 2.35 (90\% CI 1.10-5.01) and 3.59 (90\% CI 1.36-9.45) times higher, respectively. The predicted WTP value was 0.30 (0.12-0.70) times lower for those who had just started the decision-making process compared to those who were close to a decision/already decided at study entry. A sensitivity analysis was conducted removing \$5000, a value more than two standard deviations from the transformed mean; results remained consistent (Additional file 3: Table S3).

\section{Discussion}

The majority of participants in both study groups readily reported WTP for decision preparation, for the P3P intervention and for the various materials provided to participants in the UC group. Participants in both study groups were willing to pay a median value ranging from \$25-50, depending on SV. Demographic variables and participants' baseline stages of decision making predicted various WTP values suggesting differential benefit for individual characteristics.

Participant characteristics related to higher WTP values suggest which patients likely need greater decisional support. Those not married or partnered valued P3P more; men with fewer personal resources may value a decision aid more highly than a man with a partner who can share in the decision-making process. Those who had not yet or just started decision making logically indicated a higher value for decision support. Finally, the finding that participants are willing to pay more for P3P if they prefer to make shared rather than passive decisions is important. This valuation could mean that participants who were not yet ready to engage with a decision aid, had a more private decision-making style or found less value in decision aids. These WTP valuations of P3P can help to focus on future patients who would benefit most from decision aids: men not yet starting decision making, those without a partner/spouse to share in the decision process, and those open to shared decision making. Increased WTP for P3P in both lower and higher incomes, versus moderate incomes, differs from the expected direct association of WTP with ability to pay. Further work could explore detailed financial resources and WTP responses.

The demand curve for WTP demonstrated that the approach performed well in economic terms. The curve flattened at lower prices as the demand became more elastic in the presence of low-cost education substitutes.

In the UC group, the type and extent of preparatory educational materials reported was variable. It was likely more difficult to provide a consistent WTP value for a collection of various educational materials. Our finding that a lower proportion of UC participants, as compared to P3P users, were able to provide a WTP value supports this implication.

The participant characteristics associated with WTP for usual care differed from those for P3P. For UC, those with a lower level of education expressed higher WTP; perhaps perceiving a greater need for decision materials provided (or not) by the consulting physician's office. In contrast to the P3P group, UC respondents who had already decided were willing to pay more than those who had not yet or just started their decision making. This counter-intuitive result might indicate that participants who made a decision even before meeting the physician were willing to pay more for a diverse collection of non-personalized material, while those unable to make a quick decision with the available material valued such materials less. Patients will always have access to a variety of ad hoc and Internet sources and may have difficulty determining quality.

Limitations in our study are those inherent in many WTP studies: protest responses (nonresponses when unwilling to provide a value or for some zero values), preference uncertainty or the confidence of one's WTP response, and outliers [7, 24-29]. Non-response, infinity (very high valuations) and zero responses are not uncommon in WTP assessments [7, 27-29] and are difficult to interpret. Non-response is often from a lack of exposure to the product, as was the case in our study, but it also can represent a protest response, an expression of preference that is not reflective of economic assumptions underlying WTP theory [27, 28]. Halstead, et al. and others $[27,30]$ found that censoring protest responses should only occur if the characteristics of the protest responders do not differ significantly from the other respondents. Our comparisons of responders and non-responders found no particular characteristic for bias.

Zero responses also can be either a true zero WTP value or a protest vote. For example, some of the P3P participants' reasons for giving a zero value, unwillingness to pay for available internet information, suggested a protest WTP response. Although some methods have been described modeling zero values, or protest responses, to be conservative we included all zero WTP responses in our estimates [7, 27, 31]. Preference uncertainty may be caused by incomplete knowledge about product features or just uncertainty about their own preferences [32]. WTP values are less valid when preference uncertainty is high, 
such as for the UC's undefined materials, as evidenced in part by the $44 \%$ not providing a WTP value.

Another limitation, common to WTP studies is the presence of outliers. We had one main outlier in the P3P group who expressed a WTP value 100 times greater than the next highest value. There is no consensus on how outliers should be handled in WTP studies; the method largely depends on how the WTP results will be used. For analysis of characteristics associated with WTP values, removing the outliers provides the most accurate results, as we did here in all our means-based analyses. However, for inclusion in cost-benefit analyses, it is suggested to retain those outliers to represent the full range of the benefit of the intervention. An alpha-trimmed mean can also be considered [33].

Our results are limited by estimating the value of P3P alone as an adjunct to usual patient education. Although P3P's value may be additive to usual education, we cannot assume that the value of usual education would remain constant when P3P is also used.

A strength of our study was that we measured and controlled for starting point bias, common but not universal in WTP surveys that use a bidding approach. Similar to our finding that the P3P group starting with a high value was willing to pay about $\$ 42$ more than those starting low, Stalhammar [34] found a starting point bias, with a WTP of only $\$ 9$ vs $\$ 38$ for a pill taken at meals instead of before meals depending on starting with a low or high amount, respectively. Another study evaluating WTP for treatment of bleeding disorders found a median WTP of only $\$ 1500$ when bidding started at $\$ 500$ and $\$ 3500$ if started at $\$ 5000$ [8]. Starting point bias is not fully eliminated by any method that provides a direct WTP value. Future studies can use multiple approaches to explore the effects of different WTP questionnaire methods [19]. Although conjoint analyses are becoming more popular for measuring patient preferences in health care, their WTP responses are not independent of other measure attributes included in a conjoint approach.

There are very few economic studies evaluating decision aids, and fewer that use WTP for evaluating cost-benefit. One such study used WTP to determine the cost-benefit of the use of a decision support program for patients with breast cancer in a rural community [18]. This program included a trained facilitator who met with the participant before a physician visit and provided a personalized written "consultation plan" to use during the visit. WTP averaged \$150, however the cost of this labor-intensive program was high, resulting in a positive net-benefit only when the most efficient parameters were considered. We anticipate that the P3P program will have a more efficient implementation cost due to its intrinsic automation and be able to demonstrate a positive net-benefit given the high mean WTP value from participants. As WTP for P3P reported here was a demonstration of the perceived value, in future analyses we will combine this with the costs for P3P program delivery across delivery sites to determine the overall value of the P3P program in a net benefit calculation.

The WTP expressed by men making decisions after a diagnosis of localized prostate cancer demonstrated a valued decision aid, tailored to users' personal preferences and concerns and always available for return visits. Such availability is important, given the frequent reports that patients are often not prepared for cancer consultations $[18,35]$, or do not remember the content of these meetings [10, 36, 37]. The WTP for P3P was instructive, especially when further characterized by influence of demographic characteristics. Our findings suggest that single men or those with modest incomes are likely targets for decisional support. Further, men who are open to a shared decision-making style are likely eager recipients of decision support. Health care systems with limited resources could target groups with the greatest need for decision preparation and provide P3P.

\section{Conclusions}

Our study used the WTP contingent valuation technique to demonstrate that men with localized prostate cancer who were randomized to P3P, a personalized web-based decision support system, or to UC, were readily willing to pay for a decision aid. We demonstrated P3P WTP valuations that can help providers and health care systems focus on future patients who would most value P3P: men who have not yet started to make a decision, those without a partner or spouse to share the decision process, and those open to shared decision making. These results comprise the evidence needed by payers to support the adoption of P3P to support men making decisions about prostate cancer treatments.

\section{Additional files}

Additional file 1: Table S1. Actual, Transformed and Back-Transformed Willingness to Pay values for P3P and Usual Care Groups by High or Low Starting Values. Summary of the WTP values for each study group; new table requested by reviewers. (DOCX $13 \mathrm{~kb}$ )

Additional file 2: Table S2. Tobit Regression Model for P3P InterventionAll Values $<\$ 100,000$. Table detailing the starting value adjusted univariate and final multivariable for the UC group. (DOCX $17 \mathrm{~kb}$ )

Additional file 3: Table S3. Tobit Regression Model for Usual Care. Table detailing the starting value adjusted univariate and final multivariable for the P3P group. (DOCX $17 \mathrm{~kb}$ )

\section{Abbreviations}

P3P: Personal Patient Profile-Prostate; SV: starting values; UC: usual care; WTP: willingness-to-pay 


\section{Acknowledgements}

The authors wish to thank the participants who shared time and effort to contribute data in this study. Also, the authors acknowledge the consistently excellent efforts of Erica Fox, RN, during data collection and processing.

\section{Funding}

Financial support for this study was provided entirely by a grant from the National Institute of Nursing Research (R01NR009692). The funding organization had no role in design of the study and collection, analysis, or interpretation of data and no role in writing the manuscript.

\section{Availability of data and materials}

De-identified datasets used and/or analyzed during the current study are available from the corresponding author on reasonable request.

\section{Authors' contributions}

LW, FH, BH, SW, MS, PC and DB made substantial contributions to conception and design. MS, PC, GC, VM, CF, RJ and TK made substantial efforts in acquisition of data. FH and TB led the statistical analyses and all authors contributed to interpretation of data; $\mathrm{LW}, \mathrm{FH}, \mathrm{BH}, \mathrm{TB}$ and $\mathrm{DB}$ were involved in drafting the manuscript and all authors revised it critically as needed for important intellectual content; All authors gave final approval of the submitted version. Each author has participated sufficiently in the work to take public responsibility for appropriate portions of the content; All authors agreed to be accountable for aspects of the work in ensuring that questions related to the accuracy or integrity of any part of the work are appropriately investigated and resolved.

\section{Ethics approval and consent to participate}

- Dana-Farber Cancer Institute Institutional Review Board (FWA0001121) Protocol Number 12-363 (provided review for Beth Israel Deaconess Medical Center in Boston, University of Massachusetts Memorial Hospital in Worcester, and the community clinic in western New York);

- Emory University Institutional Review Board (FWA00005792) - Study Number IRB00068991 (provided review for Emory University HospitalTower and -Midtown, and Grady Memorial Hospital) and IRB00082282 (provided review for Atlanta Veterans Affairs Medical Center)

- Kaiser Permanente Southern California Institutional Review Board (FWA00002344) - Study Number 10111 (provided review for KPSC-Los Angeles and -Downey Medical Centers)

- University of Virginia Institutional Review Board for the Social and Behavioral Sciences (FWA00006183) - Project \# 2011-0172-00 (provided review for University of Virginia Health System)

- University of Texas Health Science Center at Houston Committee for the Protection of Human Subjects (FWA00000667) - UTHealth Protocol Number HSC-MS-13-0452/Harris Health System Protocol Number 13-090576 (provided review for Lyndon B Johnson Hospital)

Written informed consent was obtained from all individual participants included in the study.

\section{Consent for publication}

Not applicable.

\section{Competing interests}

The authors declare that there are no competing interest.

\section{Publisher's Note}

Springer Nature remains neutral with regard to jurisdictional claims in published maps and institutional affiliations.

\section{Author details}

'University of California San Francisco, 2130 Fulton St, San Francisco, CA 94117, USA. ${ }^{2}$ Dana-Farber Cancer Institute, 450 Brookline Avenue, Boston, MA 02215, USA. ${ }^{3}$ University of Washington, 1959 NE Pacific St, Seattle, WA 98195, USA. ${ }^{4}$ Beth Israel Deaconess Medical Center, 330 Brookline Ave, Boston, MA 02215, USA. ${ }^{5}$ Emory University School of Medicine, 1365 Clifton Rd NE, Suite B1400, Atlanta, GA 30322, USA. ${ }^{6}$ Kaiser Permanente Medical Center, 4867 Sunset Blvd, Los Angeles, CA 90027, USA. 'University of Virginia, 202 Jeanette Lancaster Way, Charlottesville, VA 22908, USA.
Received: 12 April 2018 Accepted: 17 December 2018

Published online: 09 January 2019

\section{References}

1. Wang EH, Gross CP, Tilburt JC, Yu JB, Nguyen PL, Smaldone MC, Shah ND, Abouassally R, Sun M, Kim SP. Shared decision making and use of decision AIDS for localized prostate cancer : perceptions from radiation oncologists and urologists. JAMA Intern Med. 2015;175(5):792-9.

2. Makarov DV, Chrouser K, Gore JL, Maranchie J, Neilsen ME, Saigal C, Tessier C, Fagerlin A. AUA white paper on implementation of shared decision making into urological practice. Urology Practice. 2016;3(5):355-63.

3. Stacey D, Legare F, Lewis K, Barry MJ, Bennett CL, Eden KB, Holmes-Rovner M, Llewellyn-Thomas $H$, Lyddiatt A, Thomson $R$, et al. Decision aids for people facing health treatment or screening decisions. Cochrane Database Syst Rev. 2017;4:Cd001431.

4. Berry DL, Halpenny B, Hong F, Wolpin S, Lober WB, Russell KJ, Ellis WJ, Govindarajulu U, Bosco J, Davison BJ, et al. The personal patient profileprostate decision support for men with localized prostate cancer: a multicenter randomized trial. Urol Oncol. 2013;31(7):1012-21.

5. Berry DL, Hong F, Blonquist TM, Halpenny B, Filson CP, Master VA, Sanda MG, Chang P, Chien GW, Jones RA, et al. Decision support with the personal patient profile-prostate: a multi-center randomized trial. J Urol. 2018;199:89-97.

6. Trenaman L, Bryan S, Bansback N. The cost-effectiveness of patient decision aids: A systematic review. Healthcare (Amsterdam, Netherlands). 2014;2(4): 251-7.

7. Dalmau-Matarrodona D. Alternative approaches to obtain optimal bid values in contingent valuation studies and to model protest zeros: estimating the determinants for individuals' willingness to pay for home care services in day case surgery. Health Econ. 2001;10:101-18.

8. Eastaugh SR. Willingness to pay in treatment of bleeding disorders. Int J Technol Assess Health Care. 2000;16(2):706-10

9. Johannesson M, Johannsson P, Kristrom B, Borgquist L, Jonsson B. Willingness to pay for lipid lowering: a health production function approach. Appl Econ. 2006;25(8):1023-31.

10. O'Brien MA, Charles C, Lovrics P, Wright FC, Whelan T, Simunovic M Kennedy E, Grunfeld E. Enablers and barriers to using patient decision aids in early stage breast cancer consultations: a qualitative study of surgeons' views. Implementation science : IS. 2014;9:174.

11. O'Brien B, Viramontes JL. Willingness to pay: a valid and reliable measure of health state preference? Med Decis Mak. 1994;14:289-97.

12. Cuypers M, Lamers RED, Kil PJM, van de Poll-Franse LV, de Vries M. Impact of a web-based prostate cancer treatment decision aid on patient-reported decision process parameters: results from the prostate Cancer patient centered care trial. Support Care Cancer. 2018.

13. Grunert KG, Juhl HJ, Esbjerg L, Jensen BB, Bech-Larsen T, Brunso K. Comparing methods for measuring consumer willingness to pay for a basic and an improved ready made soup product. Food Qual Prefer. 2009;20:607-19.

14. Steiner M, Hendus J. How consumers' willingness to pay is measured in practice; an empirical analysis of common approaches' relevance. SSRN. 2012:1-7.

15. Berry D, Blonquist T, Wilson L, Halpenny B, Hong F. PD17-10 assigning value to the personal patient profile-prostate decision aid: a willingness to pay analysis. J Urol. 2016;195(4):e402.

16. Berger M. Willingness to pay versus willingness to buy: what defines value in healthcare? Value Health. 1998; (4):201-3.

17. Boman M, Doctorman L. Pick a number, but not just any number: valuation uncertainty and maximum willingness to pay. J Environ Econ Policy. 2017; 6(3):283-304.

18. Wilson L, ., Loucks A, Stupar L, O'Donnell S, Moore D, Belkora J: Cost-benefit analysis of decision support methods for patients with breast cancer in a rural community. Commun Oncol 2013, 10(2):47-57.

19. Frew EJ, Wolstenholme JL, Whynes DK. Comparing willingness-to-pay: bidding game format versus open-ended and payment scale formats. Health policy (Amsterdam, Netherlands). 2004;68(3):289-98.

20. Vaughan WJ, Russell CS, Rodriguez DJ, Darling AC: Central tendency measures of willingness to pay from referendum contingent valuation data: Issures and alternatives in project analysis 1999:1-36.

21. Yee TW. Vector generalized linear and additive models: with an implementation in R. Springer, Inc: NY, NY; 2015.

22. A language and environment for statistical computing [https://www.Rproject.org/]. 
23. SAS Institute Inc: SAS 9.4 Procedures Guide. In. Cary, NC: SAS Institute Inc.; 2013.

24. Braun C, Rehdanz K, Schmidt U. Validity of willingness to pay measures under preference uncertainty. PLoS One. 2016;20:1-12.

25. Akter S, Bennett J, Akhter S. Preference uncertainty in contingent valuation. Ecol Econ. 2008;67(3):345-51 https://doi.org/10.1016/j.ecolecon.2008.07.009.

26. Kahneman D, Ritov I, Schkade D. Economic preferences or attitude expressions?: An analysis of dollar responses to public issues. J Risk Uncertainty. 1999;19(1-3):203-35.

27. Jorgensen BS, Syme GJ, Bishop BJ, Nancarrow BE. Protest responses in contingent valuation. Environ Resour Econ. 1999;14:131-50.

28. Lo AY, Jim CY. Protest response and willingness to pay for culturally significant urban trees: implications for contingent valuation method. Ecol Econ. 2015;114:58-66.

29. Bonnichsen O, Olsen SB. Correcting for non-response bias in contingent valuation surveys concerning environmental non-market goods: an empirical investigation using an online panel. J Environ Plan Manag. 2015; 59(2):245-62.

30. Halstead JM, Luloff AE, Stevens TH. Protest bidders in contingent valuation. Northeastern J Agricul Res Econ. 1992;21:160-9.

31. Strazzera E, Scarpa R, Calai P, Garrod D, Willis K. Modelling zero values and protest responses in contingent valuation survey. Appl Econ. 2013;35:133-8.

32. Ready RC, Champ PA, Lawton JL. Using respondent uncertainty to mitigate hypothetical bias in a stated choice experiment. Land Econ. 2010:363-81.

33. Mitchell RC, Carson RT: Using surveys to value public goods: The contingent valuation method. Resources for the Future 2005, New York, NY (Johns Hopkins University Press):4th printing.

34. Stalhammar N. An empirical note on willingness to pay and starting-point bias. Med Decis Mak. 1996;16:242-7.

35. Hack TF, Degner LF, Parker PA. The communication goals and needs of cancer patients: a review. Psycho-Oncology. 2005;14(10):831-45 discussion 846-837.

36. Anning JJ, Wassersug RJ, Goldenberg SL. Patient preference and the impact of decision-making aids on prostate cancer treatment choices and postintervention regret. Curr Oncol. 2012:19:1-10.

37. Sepucha KR, Simmons LH, Barry MJ, Edgman-levitan S, Licurse AM, Chaguturu SK. Ten years, forty decision aids, and thousands of patient uses: shared decision making at Massachusetts General Hospital. Health Aff. 2016; 35(4):630-6.

Ready to submit your research? Choose BMC and benefit from:

- fast, convenient online submission

- thorough peer review by experienced researchers in your field

- rapid publication on acceptance

- support for research data, including large and complex data types

- gold Open Access which fosters wider collaboration and increased citations

- maximum visibility for your research: over $100 \mathrm{M}$ website views per year

At $\mathrm{BMC}$, research is always in progress.

Learn more biomedcentral.com/submissions 